\title{
Vibrational heat capacity of collagen and collagen-water
}

\author{
Marek Pyda $^{1,4} \cdot$ Patrycja Zawada $^{1} \cdot$ Agata Drogon $^{1} \cdot$ Marcin Skotnicki ${ }^{2} \cdot$ Peggy Cebe $^{3}$
}

Received: 17 January 2019/ Accepted: 13 August 2019/Published online: 28 August 2019

(C) The Author(s) 2019

\begin{abstract}
The vibrational heat capacities of bovine collagen in the solid state, below any phase transitions (helix-coil, melting, glass transition, denaturation) in the presence and absence of water, are calculated and compared with experimental data, collected from the literature. The vibrational heat capacities of dry collagen are estimated as a sum of products of the vibrational heat capacity of the individual poly(amino acid) residues and the total number of each kind of sequence of amino acids in the macromolecule of collagen. For the individual poly(amino acid), the vibrational heat capacity is taken from Advanced Thermal Analysis System Data Bank, which was a preliminary estimation using the experimental lowtemperature heat capacities data, linked to their vibrational spectra based on the group and skeletal vibration contributions of the poly(amino acid). The difference between the experimental and calculated $C_{\mathrm{p}}$ of the dry collagen is smaller than $\pm 3 \%$. The vibrational heat capacity of the solid collagen-water system, below any phase transitions, is estimated from a sum of linear combinations of the mass fractions of the vibrational heat capacities of dry collagen and water. The vibrational calculated $C_{\mathrm{p}}$ can be used as a reference baseline for quantitative thermal analysis of experimental $C_{\mathrm{p}}$ in any phase transition obtained by scanning calorimetry for the collagen and collagen-water systems.
\end{abstract}

Keywords Collagen $\cdot$ Vibrational heat capacity $\cdot$ Collagen-water $\cdot$ Phase transition

\section{Introduction}

Collagen is one of the largest macromolecules-proteins (around $10^{6} \mathrm{Da}$ )—with both simple and regular construction in terms of size and natural origin. According to Ref. [1], there are 29 collagen types (collagen type I to XXIX) with different super-structures from fibrillar collagen (collagen I, II, XI, IX), hexagonal networks (collagen VIII

Electronic supplementary material The online version of this article (https://doi.org/10.1007/s10973-019-08697-5) contains supplementary material, which is available to authorized users.

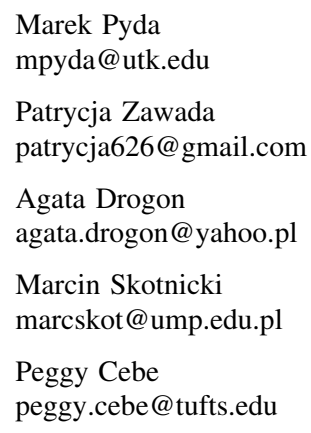

and $\mathrm{X}$ ), and beaded filaments (collagen VI) to anchoring fibrils (collagen VII). Bovine collagen, which is considered in this study, belongs to collagen type I.

The macromolecule collagen consists of three chains rolled up into a triple helix which creates its rigid fiber structures. Each chain contains approximately 1400 amino acid residues [2-5]. Every third amino acid in each chain is glycine (Gly), the smallest of the amino acids. The molecular pattern of the chain may be roughly described as (X-Y-Gly) or (Gly-X-Y), where X and Y represent other amino acids. The triple helical conformation is also

1 Department of Chemistry, Rzeszow University of Technology, Al. Powstancow Warszawy 6, 35959 Rzeszow, Poland

2 Department of Pharmaceutical Technology, Poznan University of Medical Sciences, Ul. Grunwaldzka 6, 60-780 Poznan, Poland

3 Department of Physics and Astronomy, Tufts University, 574 Boston Ave., Medford, MA 02155, USA

4 Department of Biophysics, Poznan University of Medical Sciences, Ul. Grunwaldzka 6, 60-780 Poznan, Poland 
Table 1 Amino acids in bovine collagen (collagen type I) and their parameters [5, 6]

\begin{tabular}{|c|c|c|c|c|c|}
\hline Amino acid & $\begin{array}{l}M_{\mathrm{w}} \text { molar } \\
\mathrm{mass}_{\mathrm{g} \mathrm{mol}}{ }^{-1}\end{array}$ & $\begin{array}{l}\text { Number of amino } \\
\text { acids in A1 chain }\end{array}$ & $\begin{array}{l}\text { Number of amino } \\
\text { acids in A2 chain }\end{array}$ & $\begin{array}{l}N_{\mathrm{i}} \text { Total number of amino acids in } \\
\text { collagen }(2 \mathrm{~A} 1+\mathrm{A} 2)\end{array}$ & $\begin{array}{l}\text { mass } \% \text { in } \\
\text { collagen }\end{array}$ \\
\hline Glycine (Gly) & 57.05 & 389 & 380 & 1158 & 27 \\
\hline $\begin{array}{l}\text { Proline }(\text { Pro }) / \\
\text { hydroxyproline } \\
(\text { Hyp })\end{array}$ & $114.02 / 131.13$ & 279 & 236 & 794 & 18.5 \\
\hline Alanine $(A l a)$ & 71.08 & 143 & 126 & 412 & 9.6 \\
\hline $\begin{array}{l}\text { Glutamic acid/ } \\
\text { glutamine }\end{array}$ & $129.1 / 128.11$ & $76 / 64$ & $51 / 36$ & $216 / 138$ & 8.2 \\
\hline $\begin{array}{l}\text { Aspartic acid/ } \\
\text { asparagine }\end{array}$ & $114.09 / 115.08$ & $64 / 29$ & $43 / 43$ & $171 / 101$ & 6.33 \\
\hline Arginine & 156.17 & 70 & 73 & 213 & 4.965 \\
\hline Serine & 87.06 & 58 & 54 & 170 & 3.96 \\
\hline Lysine & 128.16 & 52 & 50 & 164 & 3.82 \\
\hline Leucine & 113.15 & 50 & 60 & 160 & 3.73 \\
\hline Valine & 99.12 & 42 & 50 & 134 & 3.12 \\
\hline Threonine & 101.09 & 44 & 43 & 131 & 3.05 \\
\hline Isoleucine & 113.14 & 25 & 35 & 85 & 1.98 \\
\hline Phenylalanine & 147.16 & 24 & 23 & 71 & 1.655 \\
\hline Tyrosine/cysteine & $163.18 / 103.15$ & $16 / 18$ & $13 / 9$ & $45 / 45$ & 2.1 \\
\hline Methionine & 131.18 & 13 & 9 & 35 & 0.82 \\
\hline Histidine/tryptophan & $137.15 / 186.21$ & $9 / 6$ & $12 / 5$ & $30 / 17$ & 1.1 \\
\hline Sum: & & & & 4290 & 100 \\
\hline
\end{tabular}

dependent on the presence of proline (Pro) and hydroxyproline (Hyp) in the chain [2-5]. In addition to those three major amino acids in the collagen polypeptide chain, there is still a number of other amino acids of much lower content in comparison with those previously mentioned amino acids (see Table 1). The detailed contents of mass $\%$ of amino acid compositions for the investigated bovine collagen are presented in Table 1.

Figure 1 shows a picture of a triple helix of collagen with the three most important amino acids: glycine (Gly), proline/hydroxyproline (Pro/Hyp), and alanine (Ala) as the sequence (Gly-Pro/Hyp-Ala) in the chemical structure of bovine collagen [3-5].

The highest contents of amino acids in bovine collagen come from 27 mass\% of glycine, 18.5 mass $\%$ of proline/ hydroxyproline, and from 9.6 mass $\%$ of alanine. Both proline and hydroxyproline are rigid, cyclic amino acids that limit the rotation of the spine of the polypeptide, thereby contributing to the stabilization of the triple helix. Hydroxyproline, which is critical for maintaining the
Fig. 1 Triple helix of collagen with mass\% contents of the three most often repeating sequence amino acids: (GlyPro/Hyp-Ala) in the chemical structure of bovine collagen, type I $[4,5,7]$. Left side is colored by atom (nitrogen atoms - blue, oxygen atomsred) and right is colored to highlight the three chains. (Color figure online)

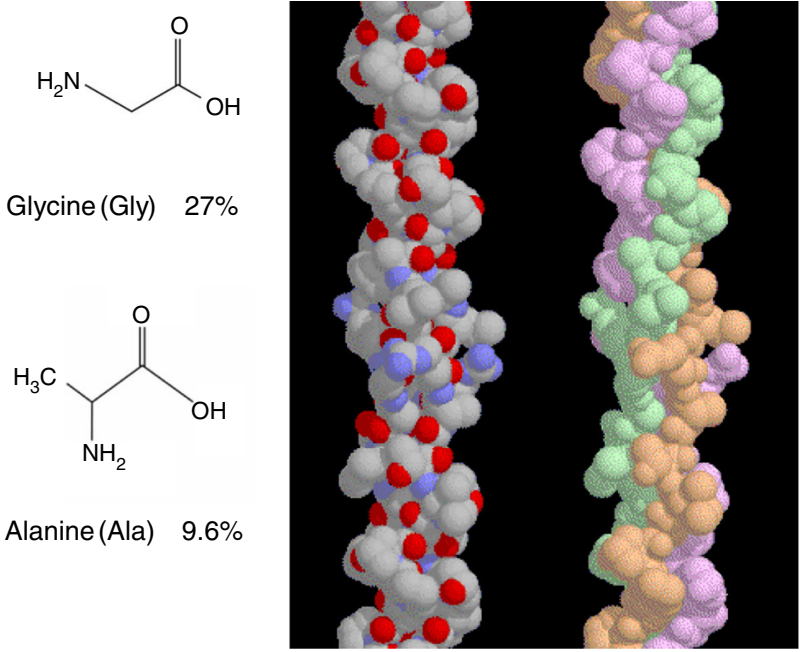

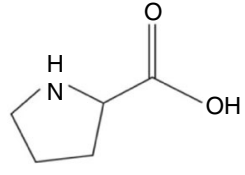

Proline (Pro) $18.5 \%$<smiles>O=C(O)C1CC(O)CN1</smiles>

Hydroxyproline (Hyp) 
stability of collagen, is formed by modifying proline after building a collagen chain. For example, this reaction requires the presence of an adequate amount of vitamin $\mathrm{C}$. The deficiency slows the production of hydroxyproline and stops the building of new collagen, which causes a disease called scurvy.

Collagen obtained from farm animals is a known ingredient for cooking. Like most other proteins, when the collagen is heated, it loses its entire structure-the triple helix grows, and the chains break apart. When the denatured collagen chains cool, they absorb all the surrounding water like a sponge to form gelatin.

As mentioned before, there are 29 collagen types which contain three main types of fibrillar collagen that form long ropes used to support building structures in the living organisms and pathways for cell movement during development. All contain long triple helix sections that differ in their different types of terminal regions $[1,3,5,8]$.

The effect of temperature on collagen macromolecules is an important issue in the study of physical properties. By simply heating and cooling, the collagen structure can be significantly changed, affecting its final biofunctions. The description of thermal properties of complex macromolecules, such as collagen, can be developed based on the knowledge of thermal properties of amino acids - similarly in approach to the study of silk molecules [9]. For many physical properties, including thermal properties, a simple additive rule can be used to predict the behavior of the macromolecule [9-11]. For example, in the case of silk and the silk-water system, the bulk property such as the vibrational heat capacity, $C_{\mathrm{p}}$ (vibration), was determined using a linear combination of $C_{\mathrm{p}}$ (vibration) of amino acid residues and the vibrational heat capacity of water $[9,12]$. By applying a similar approach, we investigate the additive rule for the vibrational heat capacity of bovine collagen, in the presence and absence of water by summing the contribution to the heat capacity from 4290 sequences of amino acids and water.

A better understanding of biomacromolecules such as bovine collagen requires knowledge of their structure and energetics. The structure of collagen has been reported in the literature $[3,7,8]$. The energetics of collagen can be determined by thermal analysis. Many reports about measurements of thermal properties for poly(amino acid)s and collagen can be found [5, 13-24]; however, only a few quantitative approaches and interpretations of the existing data on the microscopic level are available [10, 25-27]. Early work in the quantitative thermal analysis of the pure and partially hydrated biomaterial, such as silk, has been initiated by Cebe, Pyda, and co-workers [9, 11, 20, 27]. Similarly, as for silk, in order to fully understand the formation of collagen and thermodynamic processes, a proper link has to be established between the macroscopic properties and the microscopic structure and behavior. For example, the apparent heat capacity of dry collagen and collagen with water should be interpreted in terms of molecular motions of poly(amino acid)s and water $[12,25-27]$ to better understand thermal properties.

For thermal properties characterization such as heat capacity and phase transitions over a whole range of temperatures, adiabatic calorimetry (AC), differential scanning calorimetry (DSC), and temperature-modulated DSC (TMDSC) methods are often used [28-34]. Adiabatic calorimetry is applied to measure the low-temperature heat capacity of macromolecules and biomacromolecules to establish a baseline vibrational heat capacity [10, 11, 35-37]. The vibrational heat capacities for the individual amino acids and water were taken from the ATHAS Data Bank [31, 38]. The solid, vibrational heat capacities are used for quantitative thermal analysis. Such approach is useful and quick for the quantitative examination of the thermal properties of many biomacromolecules.

In this paper, we present calculations of the heat capacity of dry bovine collagen and the partially hydrated collagen-water system in terms of the vibrational motions of collagen and water that enable us to interpret the experimental data. The heat capacity from low-temperature to any phase transition region of dry collagen and collagen-water was linked to the vibrational spectra of the poly(amino acid)s and water as found in the ATHAS Data Bank [31, 38]. The total calculated vibrational heat capacity of collagen and the collagen-water system has been extended to high temperatures and can be used as the reference line (baseline) in the transition regions for quantitative thermal analysis for coming study.

\section{Calculation of the heat capacity for the solid state of dry collagen}

The vibrational solid heat capacity of collagen and the collagen-water system was determined by assuming that at sufficiently low temperature before reaching any phase transition region, only vibrational motions contribute to the heat capacity [9, 39, 40]. Using this commonly acceptable assumption, the vibrational heat capacity of dry collagen, $C_{\mathrm{p}}^{\text {Collagen }}$, is calculated as a sum of products of the vibrational heat capacity of the individual poly(amino acid) residues, $C_{\mathrm{p}}(i)$, and the total number of each kind of sequence of amino acids $\left(N_{\mathrm{i}}\right)$ in the macromolecule of collagen and is written as [9]:

$$
\begin{aligned}
C_{\mathrm{p}}^{\text {Collagen }}= & N_{\mathrm{Gly}} C_{\mathrm{p}}(\mathrm{Gly})+N_{\mathrm{Pro}} C_{\mathrm{p}}(\text { Pro })+\cdots \\
& +N_{\mathrm{Met}} C_{\mathrm{p}}(\mathrm{Met}) \\
= & \sum_{\mathrm{i}} N_{\mathrm{i}} C_{\mathrm{p}}(i)
\end{aligned}
$$


The total number $\left(N_{\mathrm{i}}\right)$ of each type of amino acid is found in Ref. [5, 6] and is presented in Table 1, where $i=$ Gly, Ala, Pro,..., Met, according to the notation in Table 1 . Heat capacity, $C_{\mathrm{p}}(i)$, is the vibrational heat capacity of the repeating unit of the $i$ th-kind of poly(amino acid) in the solid state which was collected and is available in the ATHAS Data Bank for biomaterials [31, 38].

The computation of the vibrational heat capacity of each poly(amino acid) and water used for calculation of $C_{\mathrm{p}}^{\text {Collagen }}$ and $C_{\mathrm{p}}^{\text {Collagen-water }}$ was based on the Advanced Thermal Analysis System (ATHAS) scheme, which was first used for synthetic polymers from the well-established methods found in the literature [30, 38, 41-43].

In short, a general scheme of this computation of the vibrational heat capacity for each poly(amino acid) is presented below. Upon the assumption that at sufficiently low temperature below the glass transition region (Ref. [44]) only vibrational motions contribute to the heat capacity of poly(amino acid), the experimental low-temperature heat capacities at constant pressure $C_{\mathrm{p}}(\exp )$ should be converted into heat capacities at constant volume, $C_{\mathrm{v}}(-$ exp), using the standard thermodynamic relationship $[28,41-43]$ :

$C_{\mathrm{p}}(\exp )=C_{\mathrm{V}}(\exp )+T V \frac{\alpha^{2}}{\beta}$

where $T$ is temperature, $V$ is volume, and $\alpha$ and $\beta$ are the coefficients of thermal expansion and compressibility, respectively. They should be considered as functions of temperature. In the case where $\alpha$ and $\beta$ are not available, the heat capacity can be estimated using the Nernst-Lindemann approximation as follows [28, 41, 43]:

$C_{\mathrm{p}}(\exp )-C_{\mathrm{V}}(\exp )=3 R A_{0} \frac{C_{\mathrm{p}}^{2}}{C_{\mathrm{V}}} T / T_{\mathrm{m}}$

where $R$ is the universal gas constant, $A_{0}$ equals $3.9 \times 10^{-3}\left(\mathrm{~K} \mathrm{~mol} \mathrm{~J}^{-1}\right)$, and $T_{\mathrm{m}}$ is the equilibrium melting temperature.

The experimental, low-temperature heat capacity was linked to the spectrum of vibrational motions. The vibrational spectra of the solid state of each kind of the repeating unit of the poly(amino acid) consist of $3 N$ vibrators, with $N$ representing the total number of atoms in the repeating unit of the poly(amino acid). The total $3 N$ vibrators were separated into group, $N_{\mathrm{gr}}$, and skeletal, $N_{\mathrm{sk}}$, vibrations ( $3 N=N_{\mathrm{gr}}+N_{\mathrm{sk}}$ ). The numbers and types of group vibrations $\left(N_{\mathrm{gr}}\right)$ were derived from the chemical structure of the sample as a series of single frequencies and box frequencies over narrow frequency ranges. These frequencies can be evaluated from normal-mode calculations on repeating units of the poly(amino acid)s based on a fit to experimental infrared and Raman frequencies, or from

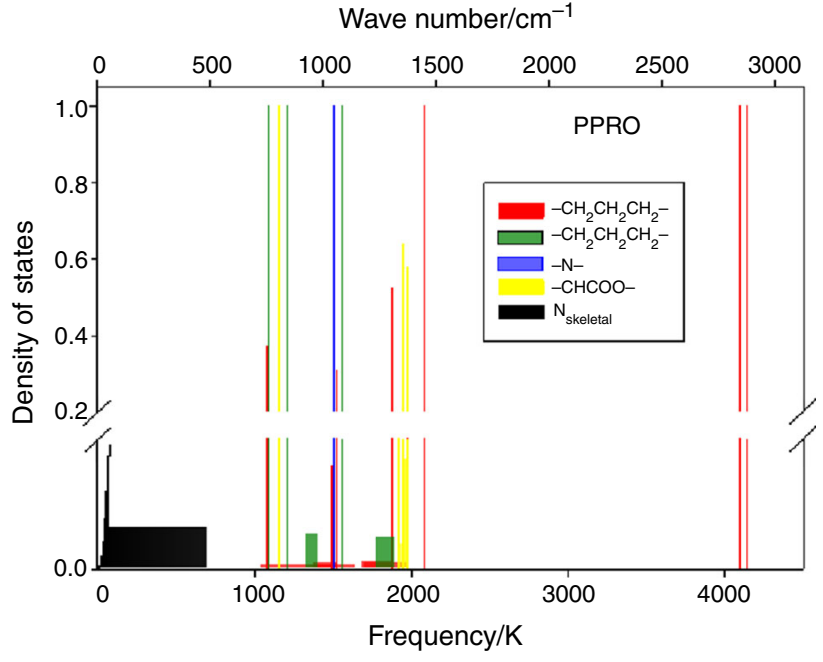

Fig. 2 The density of states of the vibration spectra for poly(Lproline) $[25,26,40]$. (Color figure online)

suitable low molar mass analogues. All approximated group vibrational frequencies of the poly(amino acid)s that are relevant to collagen and similarly for water have been collected from the ATHAS Data Bank and from the literature [28, 31, 38].

Figure 2 shows an example of the vibration spectra for poly(amino acid), i.e., poly(L-proline), with chemical structure: $\left(\mathrm{N}-\mathrm{CH}_{2}-\mathrm{CH}_{2}-\mathrm{CH}_{2}-\mathrm{CHCO}\right)_{\mathrm{n}}$, where $3 \mathrm{~N}$ is equal to 42 vibrators for total number of 14 atoms in the repeating unit, which can be separated into $N_{\mathrm{gr}}=31$ and $N_{\mathrm{sk}}=11$. The contribution of the skeletal vibrations comes from frequencies below $700 \mathrm{~K}$ (or $500 \mathrm{~cm}^{-1}$ ) and group vibrations from frequencies in the range between 1000 and $4500 \mathrm{~K}$ (or 750 and $3000 \mathrm{~cm}^{-1}$ ) [25, 26, 40].

For low temperature, the experimental heat capacity, $C_{\mathrm{v}}(\exp )$, contains only vibrational contributions and can be separated into two contributions of the heat capacities coming from group, $C_{\mathrm{v}}$ (group), and skeletal, $C_{\mathrm{v}}$ (skeletal), vibrations $[28,41]$ :

$C_{\mathrm{V}}(\exp )=C_{\mathrm{V}}($ group $)+C_{\mathrm{V}}($ skeletal $)$

The heat capacity from the group vibrations, $C_{\mathrm{v}}($ group $)$, of the poly(amino acid)s was estimated by the sum of the heat capacity from a series of single and box frequencies and is written as [28, 41]:

$C_{\mathrm{V}}($ group $)=C_{\mathrm{V}}($ Einstein $)+C_{\mathrm{V}}($ box $)$

To evaluate the heat capacity from group vibrations, Eqs. (6) and (7) are used. The heat capacity from single frequencies arising from normal modes (Einstein modes) is given by a sum of the Einstein function [28, 38, 42]: 


$$
\begin{aligned}
C_{\mathrm{V}}(\text { Einstein }) / N R & =\sum_{\mathrm{i}} E\left(\Theta_{\mathrm{Ei}} / T\right) \\
& =\sum_{\mathrm{i}} \frac{\left(\Theta_{\mathrm{Ei}} / T\right)^{2} \exp \left(\Theta_{\mathrm{Ei}} / T\right)}{\left[\exp \left(\Theta_{\mathrm{Ei}} / T\right)-1\right]^{2}}
\end{aligned}
$$

where the summation takes place on the individual modes, and $\Theta_{\mathrm{Ei}}=h v_{\mathrm{i}} / k$ is the Einstein frequency in kelvins, and $h$ and $k$ are the Planck and Boltzmann constants, respectively. The heat capacity of a box distribution, $C_{\mathrm{v}}($ box $)$, is given by a box-like spectrum, and each box is represented by a sum of one-dimensional Debye functions, $\mathbf{D}_{1}$, for the sets of vibrations within the frequency interval from $\Theta_{\mathrm{L}}$ to $\Theta_{\mathrm{U}}[28,38,42]$ :

$$
\begin{aligned}
C_{\mathrm{V}}(\text { box }) / N R= & B\left(\Theta_{\mathrm{U}} / T, \Theta_{\mathrm{L}} / T\right) \\
= & \frac{\Theta_{\mathrm{U}}}{\Theta_{\mathrm{U}}-\Theta_{\mathrm{L}}}\left[\mathbf{D}_{1}\left(\Theta_{\mathrm{U}} / T\right)\right. \\
& \left.-\left(\Theta_{\mathrm{L}} / \Theta_{\mathrm{U}}\right) \mathbf{D}_{1}\left(\Theta_{\mathrm{L}} / T\right)\right]
\end{aligned}
$$

where $\Theta_{\mathrm{L}}=h v_{\mathrm{L}} / k$ is the lower frequency and $\Theta_{\mathrm{U}}=$ $h v_{\mathrm{U}} / k$ is the upper frequency in kelvins, respectively, in the box-like spectrum.

After subtracting the heat capacity of the group vibration, $C_{\mathrm{v}}$ (group), from the total experimental heat capacity, $C_{\mathrm{v}}(\exp )$, the experimental part from the skeletal contribution $C_{\mathrm{v}}$ (skeletal) remains [see Eq. (4)] and is fitted at low temperature to the general Tarasov function $\mathbf{T}$ $[28,38,41,45]$ :

$$
\begin{aligned}
C_{\mathrm{V}}(\text { skeletal }) / N_{\mathrm{sk}} R= & \mathbf{T}\left(\Theta_{1} / T, \Theta_{2} / T, \Theta_{3} / T\right) \\
= & \mathbf{D}_{1}\left(\Theta_{1} / T\right)-\left(\Theta_{2} / \Theta_{1}\right)\left[\mathbf{D}_{1}\left(\Theta_{2} / T\right)\right. \\
& \left.-\mathbf{D}_{2}\left(\Theta_{2} / T\right)\right]-\left(\Theta_{3}^{2} / \Theta_{1} \Theta_{2}\right)\left[\mathbf{D}_{2}\left(\Theta_{3} / T\right)\right. \\
& \left.-\mathbf{D}_{3}\left(\Theta_{3} / T\right)\right]
\end{aligned}
$$

to obtain the three characteristic Debye temperatures $\Theta_{1}$, $\Theta_{2}$, and $\Theta_{3}$, for each poly(amino acid) of collagen that represent the maximum frequencies of the corresponding distribution of the density of states. In Eq. (8), the theta temperatures are such that $\Theta=h v / k$ with the Debye frequencies expressed in kelvins. The functions $\mathbf{D}_{1}, \mathbf{D}_{2}$, and $\mathbf{D}_{3}$, are the one-, two-, and three-dimensional Debye functions, respectively [28, 41, 46], and represent heat capacity in the form:

$$
\begin{aligned}
C_{\mathrm{V}} / N R & =D_{\mathrm{i}}\left(\Theta_{\mathrm{i}} / T\right) \\
& =i\left(T / \Theta_{\mathrm{i}}\right)^{\mathrm{i}} \int_{0}^{\Theta_{\mathrm{i}} / T} \frac{(\Theta / T)^{\mathrm{i}+1} \exp (\Theta / T)}{[\exp (\Theta / T)-1]^{2}} \mathrm{~d}(\Theta / T)
\end{aligned}
$$

where $i$ is equal to 1,2 , or 3 . In Eq. (9), $N$ denotes the number of the vibrational modes for a given Debye frequency distribution. The temperatures $\Theta_{1}$ and $\Theta_{2}$ correspond to the constant and linear distribution of density of states with frequency, respectively. The temperature $\Theta_{3}$ describes skeletal contributions with a quadratic frequency distribution for small molecules and atoms as found in all solids $[28,41]$.

Knowing the Debye temperatures $\Theta_{1}, \Theta_{2}$, and $\Theta_{3}$, from a best fit of the experimental data, the skeletal heat capacities, $C_{\mathrm{v}}$ (skeletal), were calculated in the whole range of temperature. Then, by adding the group vibration heat capacity to the calculated skeletal heat capacity, the total heat capacity at constant volume, $C_{\mathrm{v}}($ total), was obtained in the solid state. Note that in Eq. (3), $C_{\mathrm{v}}$ (total) is equal to $C_{\mathrm{v}}(\exp )=C_{\mathrm{v}}$. Next, using Eq. (3), $C_{\mathrm{v}}($ total) was converted to heat capacity at constant pressure, $C_{\mathrm{p}}$, which will be noted below as $C_{\mathrm{p}}(\mathrm{vib})$ or $C_{\mathrm{p}}$ (vibration).

Figure 3 presents an example of the vibrational heat capacity, $C_{\mathrm{p}}$ (vibration), of poly(L-proline), PLPRO, as a function of temperature compared with the experimental data of $C_{\mathrm{p}}(\exp )$ from differential scanning calorimetry (DSC), both of which can be obtained from the ATHAS data bank [25-27, 31, 38, 40]. The calculation of $C_{\mathrm{p}}$ (vibration) for poly(L-proline) was made first, by the determination of the skeletal heat capacity, $C_{\mathrm{v}}$ (skeletal), for eleven skeletal modes of vibration, $N_{\mathrm{sk}}=11$, using three characteristic Debye parameters $\Theta_{1},=691 \mathrm{~K}, \Theta_{2},=\Theta_{3},-$ $=68 \mathrm{~K}$, and then by estimation of the heat capacity, $C_{\mathrm{v}}$ (group), using $N_{\mathrm{gr}}=31$ group vibrations with frequencies presented in Fig. 2. Next, by applying the universal constant $A_{\mathrm{o}}=3.9 \times 10^{-3}\left(\mathrm{~K} \mathrm{~mol} \mathrm{~J}^{-1}\right)$, the equilibrium melting temperature, $T_{\mathrm{m}}=573 \mathrm{~K}$, and molecular mass of the repeating unit for PLPRO, $M_{\mathrm{w}}=97.18 \mathrm{~g} \mathrm{~mol}^{-1}$, the heat capacity at constant volume was converted to heat capacity at constant pressure according to Eq. (3) and Refs. $[26,38,43]$.

Similarly, such a calculation of vibrational heat capacity, $C_{\mathrm{p}}$ (vibration), was obtained for each other type of

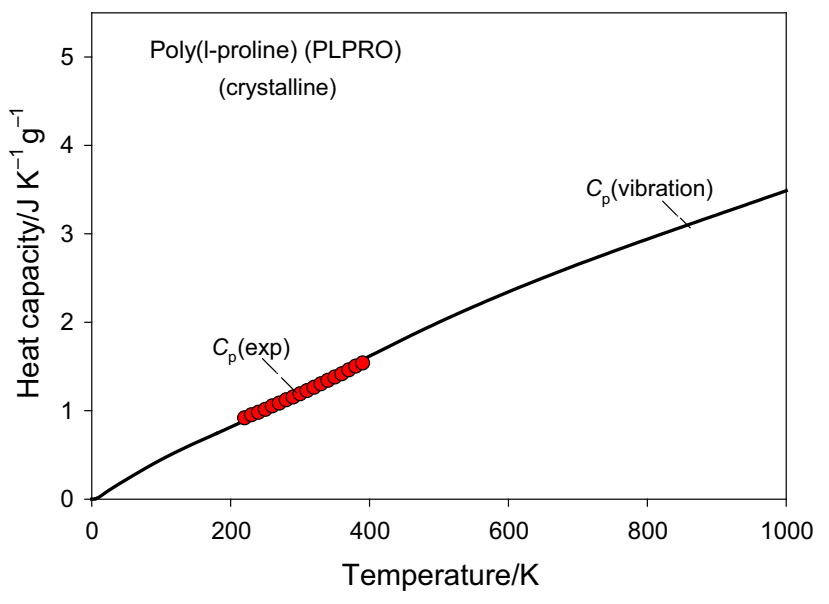

Fig. 3 The calculated vibrational heat capacity, $C_{\mathrm{p}}$ (vibration), of poly(L-proline) compared with the experimental data $C_{\mathrm{p}}(\exp )$ from Refs. [25-27, 31, 38, 40] 
poly(amino acid), $C_{\mathrm{p}}$ (vibration) $\equiv C_{\mathrm{p}}(i)$, over the rage of temperature $T=(0.1-1000) \mathrm{K}$. Finally, using Eq. (1), the total vibrational heat capacity of dry collagen, $C_{\mathrm{p}}^{\text {Collagen }}$ (vibration), was calculated. This heat capacity, $C_{\mathrm{p}}^{\text {Collagen (vibration), serves as the reference baseline to }}$ estimate additional heat capacity contributions to the experimental apparent heat capacity of collagen in the whole range of temperature for all states.

The calculated vibrational heat capacity of individual poly(amino acid)s and more complex biomaterials such as collagen can serve as a baseline reference heat capacity for the advance thermal analysis in whole range of temperature to judge any deviation from apparent heat capacity in all kinds of phase transitions such as denaturation, melting transition and the glass transition, or glass-like transition. For example, Miles [47] reports the denaturation process for dry collagen type $\mathrm{I}$ is around $500 \mathrm{~K}$ and for fully hydrated collagen is at around $335 \mathrm{~K}$. It should be noted that according to Ref. [44], the glass transition for dry poly(amino acid)s such as poly(L-methionine) and poly(Lserine) was estimated at a temperature of $280 \mathrm{~K}$ and $310 \mathrm{~K}$, respectively. In Ref. [20], the glass transition for dry rate tail collagen was found at $T_{\mathrm{g}}$ of $477 \mathrm{~K}$ measured by standard TMDSC and by quasi TMDSC around $463 \mathrm{~K}$ in Ref. [48]. For all the above examples, the vibrational heat capacity can be applied as a reference line in the advance thermal analysis.

\section{Calculation of the heat capacity for the solid state of the collagen-water system}

The heat capacities of the solid collagen-water system below any phase transition including the glass transition, $T_{\mathrm{g}}$, from vibrational motions were calculated from the linear combination of the mass or molar fractions of the vibrational heat capacity of collagen, $C_{\mathrm{p}}^{\text {Collagen (vibration), }}$ and water, $C_{\mathrm{p}}^{\text {Water }}$ (vibration), according to the equation [9-12, 48-50]:

$$
\begin{aligned}
C_{\mathrm{p}}^{\text {Collagen-Water }}(\text { vibration })= & f_{\mathrm{S}} C_{\mathrm{p}}^{\text {Collagen }}(\text { vibration }) \\
& +f_{\mathrm{W}} C_{\mathrm{p}}^{\text {Water }}(\text { vibration })
\end{aligned}
$$

where $f_{\mathrm{S}}$ and $f_{\mathrm{W}}$ are the mass fractions of collagen and water, respectively, in the collagen-water system.

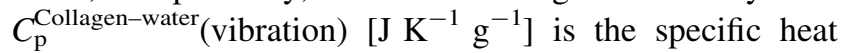
capacity of the mixture and is related to the molar heat

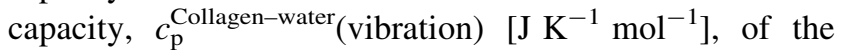
collagen-water mixture given by:

$$
\begin{aligned}
c_{\mathrm{p}}^{\text {Collagen-Water }}(\text { vibration })= & C_{\mathrm{p}}^{\text {Collagen-Water }}(\text { vibration }) M_{\mathrm{W}}(c \\
& -w)
\end{aligned}
$$

where $M_{\mathrm{w}}(c-w)$ is the molar mass of the mixture and is calculated from:

$M_{\mathrm{w}}(c-w)=X_{\mathrm{S}} M_{\mathrm{w}}($ collagen $)+X_{\mathrm{W}} M_{\mathrm{w}}($ water $)$

where $M_{\mathrm{w}}$ (collagen) and $M_{\mathrm{w}}$ (water) are the molar masses of collagen and water, respectively, and $X_{\mathrm{S}}$ and $X_{\mathrm{w}}$ are the molar fractions of collagen and water, respectively.

The vibrational heat capacity of water, $C_{\mathrm{p}}^{\text {Water }}$ (vibration), which is used in Eq. (10) was earlier described in Refs. [8-11]. In the similar manner, solid state of each poly(amino acid), $C_{\mathrm{p}}^{\text {Water }}$ (vibration), was evaluated based on the low-temperature experimental data for the heat capacity of glassy water measured by Suga and co-workers [12]. For the calculation of the vibrational heat capacity of water, the 9 degrees of freedom resulting from the 3 atoms of the molecule $\mathrm{H}_{2} \mathrm{O}$ were separated into the 3 group vibrations and 6 skeletal vibrations. The group vibrational frequencies of glassy water were taken from normal-mode calculations based on the experimental infrared and Raman spectra (O$\mathrm{H}$ symmetric stretch, with frequency $4685 \mathrm{~K}$; O-H asymmetric stretch, with frequency $4685 \mathrm{~K}$; and $\mathrm{H}-\mathrm{O}-\mathrm{H}$ deformation with frequency $2365 \mathrm{~K}$ ) as given in Ref. [8]. The remaining 6 vibrational modes contribute to the skeletal heat capacity, which was calculated by fitting the experimental data of low-temperature $C_{\mathrm{p}}$ with the general Tarasov Eq. (8). With the three Debye temperatures $\Theta_{1}$, $\Theta_{2}$, and $\Theta_{3}$ resulting from the best fit of this experimental low-temperature $C_{\mathrm{p}}$ and with parameters $N_{\mathrm{sk}}$ and $A_{0}$, the $C_{\mathrm{V}}^{\text {Water }}$ (skeletal) was estimated. Next, by adding group vibration contribution, $C_{\mathrm{V}}^{\mathrm{Water}}$ (group), to the skeletal vibration contribution, $C_{\mathrm{V}}^{\mathrm{Water}}$ (skeletal), the total heat capacity of water at constant volume, $C_{\mathrm{V}}^{\text {Water }}$ (total), was obtained. Finally, using Eq. (3), the heat capacity at constant pressure, $C_{\mathrm{p}}^{\text {Water }}$ (vibration), for water was calculated. This vibrational heat capacity for water, $C_{\mathrm{p}}^{\text {Water }}$ (vibration), was used in the construction of the vibrational heat capacity of the collagen-water system, $C_{\mathrm{p}}^{\text {Collagen-water }}$ (vibration), as shown in Eq. (10).

It should be noted that the calculation of the vibrational heat capacity of water, $C_{\mathrm{p}}^{\text {Collagen-water }}$ (vibration), was conducted in Refs. [9-11] using the low-temperature experimental heat capacity of glassy water (amorphous ice) below $T_{\mathrm{g}}=135 \mathrm{~K}$ based on data from Ref. [12]. This $C_{\mathrm{p}}^{\text {Collagen-water (vibration) still is valid for crystalline water }}$ and bound or free water. Our conclusion is based on the fact that the values of the low-temperature experimental heat capacity of glassy water and crystalline water (cube, hexagonal ice) below $T_{\mathrm{g}}$ are similar (Ref. [12]) and have 
the same vibration motion of the molecule $\left(\mathrm{H}_{2} \mathrm{O}\right)$. In this sense, the $C_{\mathrm{p}}^{\text {Collagen-water }}$ (vibration) does not depend on amount or form of water: amorphous, crystalline, bound or free water in the system of collagen-water. Such vibrational heat capacity of water was preliminarily applied successfully for the construction of the vibrational heat capacity of silk-water [9], and starch-water [10] systems. Thus, this approach was applied to calculate for the collagen-water system according to Eq. (10).

\section{Results and discussion}

Bovine collagen with a molecular mass around $M=406,940.3 \mathrm{~g} \mathrm{~mol}^{-1}$ was used as an example for the determination of the vibrational heat capacity of collagen and the collagen-water system.

The investigated collagen (collagen type I) is composed of three polypeptide chains with known sequences of 4290 amino acids. Symbolically, we can write that total collagen contains two chains of $\mathrm{A} 1$ and one of $\mathrm{A} 2$ as collagen $(\mathrm{A} 1 \times 2+\mathrm{A} 2)$, indicating that the chain $\mathrm{A} 1$ is $\mathrm{CO} 1 \mathrm{~A} 1$ BOVIN (P02453), and the chain A2 is CO1A2 BOVIN (P02456). Both the composition and content of individual poly(amino acid) residues occurring in the polypeptide chains forming the investigated collagen are presented in Table 1, for type A1 and A2 chain of collagen type I $[5,6]$.

Next, the vibrational heat capacity of dry collagen, $C_{\mathrm{p}}^{\text {Collagen }}$ (vibration), was calculated according to Eq. (1), knowing the vibrational heat capacity as a function of temperature for each type of amino acid in the bovine

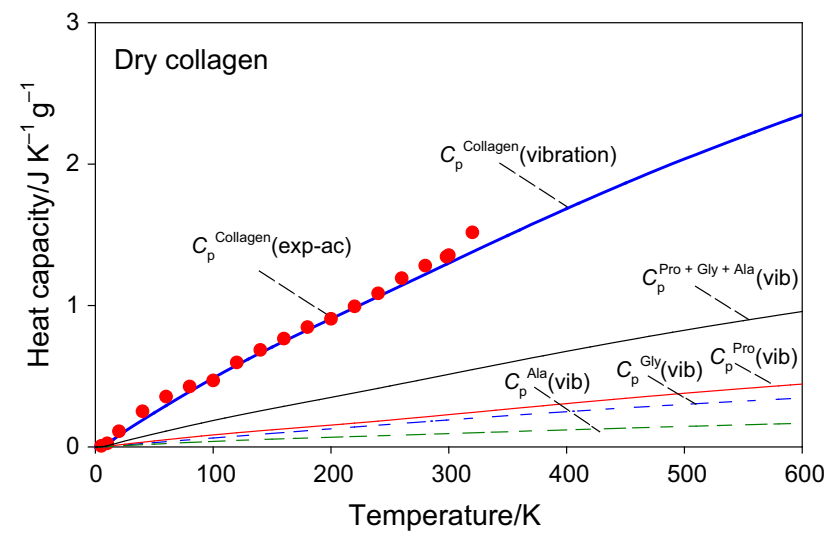

Fig. 4 The calculated vibrational heat capacity of dry bovine collagen, $C_{\mathrm{p}}^{\text {Collagen }}$ (vibration), and its three major contributions from the amino acids, proline (Pro), $C_{\mathrm{p}}^{\text {Pro }}$ (vib), glycine (Gly), $C_{\mathrm{p}}^{\mathrm{Gly}}(\mathrm{vib})$, and alanine (Ala), $C_{\mathrm{p}}^{\text {Ala }}$ (vib), as a function of temperature. Also, the sum of these three vibrational heat capacities, $C_{\mathrm{p}}^{\text {Pro-Gly-Ala }}(\mathrm{vib})$, is plotted. The experimental low-temperature heat capacities, $C_{\mathrm{p}}^{\text {collagen }}(\exp -\mathrm{ac})$ (full circles), of dry bovine collagen as a function of temperature from 5 to $320 \mathrm{~K}$, measured by adiabatic calorimetry as described in the literature [18, 24], are compared to the calculated vibrational heat capacity, $C_{\mathrm{p}}^{\text {Collagen }}$ (vibration) (solid line) collagen and their corresponding numbers $N_{\mathrm{i}}$ (see Table 1). The vibrational $C_{\mathrm{p}}$ of individual amino acids was evaluated using the vibrational motion spectra for the repeating unit of poly(amino acid)s from the Advanced Thermal Analysis System (ATHAS) Data Bank $[31,38]$. The vibrational $C_{\mathrm{p}}$ of the poly(amino acid)s collected in the Data Bank $[31,38]$ was calculated previously by Wunderlich and coworkers [25-27]. An example of the vibration spectra for the repeating unit of individual poly(amino acid) such as poly(L-proline) is illustrated in Fig. 2, and the vibrational heat capacity of this poly(L-proline), $C_{\mathrm{p}}$ (vibration), is presented in Fig. 3.

The vibrational heat capacity of collagen, $C_{\mathrm{p}}^{\text {Collagen }}$ (vibration), was calculated over the whole range of temperature from 0.1 to $1000 \mathrm{~K}$. The values of calculated vibrational heat capacity of dry collagen are presented in Fig. 4 and collected in Table 2.

Figure 4 presents the calculated vibrational heat capacity of bovine collagen, $C_{\mathrm{p}}^{\text {Collagen }}$ (vibration), versus temperature (solid curve) from 0.1 to $600 \mathrm{~K}$. Also, in Fig. 4, the vibrational heat capacity of three major contributors of amino acids: glycine (Gly), $C_{\mathrm{p}}^{\mathrm{Gly}}(\mathrm{vib})$, proline(Pro)/hydroxyproline (Hyp), $C_{\mathrm{p}}^{\mathrm{Pro}}(\mathrm{vib})$, and alanine (Ala), $C_{\mathrm{p}}^{\mathrm{Ala}}(\mathrm{vib})$, is plotted. Their sum gives around $41 \%$ of the total contribution to $C_{\mathrm{p}}^{\text {Collagen (vibration). The total calculated }}$ vibrational heat capacity of bovine collagen, $C_{\mathrm{p}}^{\text {Collagen }}$ (vibration), comes from the total number $\left(\sum N_{\mathrm{i}}\right)$ of the amino acids in dry collagen. The number $\left(N_{\mathrm{i}}\right)$ of the individual type of amino acids can be found in Refs. [5, 6] and gives a total number $\left(\sum N_{\mathrm{i}}\right)$ of 4290 for all of the amino acid content in the bovine collagen. The individual number $\left(N_{\mathrm{i}}\right)$ of the amino acids in bovine collagen is listed in Table 1. For example, a total of 1158 molecules of glycine (389 molecules of glycine (Gly) in the A1 chain and the 380 molecules of glycine in the A2 chain), were taken into account to determine the total glycine contribution to the total vibrational heat capacity of dry bovine collagen, $C_{\mathrm{p}}^{\text {Collagen (vibration). Similarly, the total } 794 \text { molecules of }}$ proline (Pro) give their contribution to the total vibrational heat capacity of dry bovine collagen, $C_{\mathrm{p}}^{\text {Collagen }}$ (vibration). All other numbers for all amino acid contents in the bovine collagen, which contribute to the total vibrational heat capacity, are listed in Table 2.

Figure 4 presents also the experimental low-temperature heat capacity versus temperature for dry bovine collagen; data were collected from Refs. [18, 24]. Additionally, the values of these data are listed in Table S1 (Supplementary data). These low-temperature heat capacities from adiabatic calorimetry are compared in Fig. 4 with the calculated vibrational heat capacity of solid dry bovine collagen (solid line). Good agreement between the experimental data and the calculated vibrational heat capacity of dry bovine collagen was observed for low-temperature 
Table 2 Vibrational calculated heat capacity of dry bovine collagen

\begin{tabular}{|c|c|c|c|c|c|}
\hline $\begin{array}{l}\text { Temperature/ } \\
\mathrm{K}\end{array}$ & $\begin{array}{l}{ }^{\mathrm{a}} \text { Molar heat capacity } C_{\mathrm{p}} / \\
\mathrm{J} \mathrm{K}^{-1} \mathrm{~mol}^{-1}\end{array}$ & $\begin{array}{l}\text { Specific heat capacity } C_{\mathrm{p}} / \\
\mathrm{J} \mathrm{K}^{-1} \mathrm{~g}^{-1}\end{array}$ & $\begin{array}{l}\text { Temperature/ } \\
\mathrm{K}\end{array}$ & $\begin{array}{l}{ }^{a} \text { Molar heat capacity } C_{\mathrm{p}} / \\
\mathrm{J} \mathrm{K}^{-1} \mathrm{~mol}^{-1}\end{array}$ & $\begin{array}{l}\text { Specific heat capacity } C_{\mathrm{p}} \\
\mathrm{J} \mathrm{K}^{-1} \mathrm{~g}^{-1}\end{array}$ \\
\hline 0.1 & 0.00 & 0 & 380 & $655,024.15$ & 1.6096 \\
\hline 0.2 & 0.00 & 0 & 390 & $670,248.22$ & 1.6470 \\
\hline 0.3 & 0.00 & 0 & 400 & $685,654.96$ & 1.6849 \\
\hline 0.4 & 0.00 & 0 & 410 & $700,537.85$ & 1.7215 \\
\hline 0.5 & 0.38 & 0.0000009 & 420 & $715,299.50$ & 1.7578 \\
\hline 0.6 & 2.86 & 0.000007 & 430 & $730,059.41$ & 1.7940 \\
\hline 0.7 & 3.54 & 0.000009 & 440 & $744,619.62$ & 1.8298 \\
\hline 0.8 & 4.38 & 0.00001 & 450 & $759,094.62$ & 1.8654 \\
\hline 0.9 & 8.19 & 0.00002 & 460 & $773,439.69$ & 1.9006 \\
\hline 1 & 10.21 & 0.00003 & 470 & $787,674.91$ & 1.9356 \\
\hline 1.2 & 18.13 & 0.00004 & 480 & $801,545.17$ & 1.9697 \\
\hline 1.4 & 28.55 & 0.00007 & 490 & $815,392.34$ & 2.0037 \\
\hline 1.6 & 41.36 & 0.0001 & 500 & $828,634.19$ & 2.0363 \\
\hline 1.8 & 60.33 & 0.0001 & 510 & $841,491.87$ & 2.0679 \\
\hline 2 & 82.13 & 0.0002 & 520 & $854,587.69$ & 2.1000 \\
\hline 3 & 278.00 & 0.0007 & 530 & $867,674.11$ & 2.1322 \\
\hline 4 & 658.50 & 0.0016 & 540 & $880,630.24$ & 2.1640 \\
\hline 5 & 1283.69 & 0.0032 & 550 & $893,457.62$ & 2.1956 \\
\hline 6 & 2202.70 & 0.0054 & 560 & $906,368.36$ & 2.2273 \\
\hline 7 & 3429.90 & 0.0084 & 570 & $918,915.02$ & 2.2581 \\
\hline 8 & 4964.99 & 0.0122 & 580 & $931,377.74$ & 2.2887 \\
\hline 9 & 6771.93 & 0.0166 & 590 & $943,665.89$ & 2.3189 \\
\hline 10 & 8797.98 & 0.0216 & 600 & $956,012.55$ & 2.3493 \\
\hline 15 & $20,586.16$ & 0.0506 & 610 & $968,146.75$ & 2.3791 \\
\hline 20 & $32,804.82$ & 0.0806 & 620 & $980,118.91$ & 2.4085 \\
\hline 25 & $44,519.54$ & 0.1094 & 630 & $991,931.94$ & 2.4375 \\
\hline 30 & $55,718.94$ & 0.1369 & 640 & $1,003,637.03$ & 2.4663 \\
\hline 40 & $77,178.19$ & 0.1897 & 650 & $1,015,244.38$ & 2.4948 \\
\hline 50 & $98,025.74$ & 0.2409 & 660 & $1,026,765.29$ & 2.5231 \\
\hline 60 & $118,575.76$ & 0.2914 & 670 & $1,038,193.11$ & 2.5512 \\
\hline 70 & $138,960.18$ & 0.3415 & 680 & $1,049,534.77$ & 2.5791 \\
\hline 80 & $159,058.11$ & 0.3909 & 690 & $1,060,790.49$ & 2.6067 \\
\hline 90 & $178,746.99$ & 0.4392 & 700 & $1,072,663.04$ & 2.6359 \\
\hline 100 & $198,087.27$ & 0.4868 & 710 & $1,083,115.89$ & 2.6616 \\
\hline 110 & $216,891.71$ & 0.5330 & 720 & $1,094,221.58$ & 2.6889 \\
\hline 120 & $235,177.12$ & 0.5779 & 730 & $1,105,178.52$ & 2.7158 \\
\hline 130 & $252,912.53$ & 0.6215 & 740 & $1,116,126.64$ & 2.7427 \\
\hline 140 & $270,287.03$ & 0.6642 & 750 & $1,127,009.55$ & 2.7695 \\
\hline 150 & $287,183.67$ & 0.7057 & 760 & $1,137,766.34$ & 2.7959 \\
\hline 160 & $303,895.33$ & 0.7468 & 770 & $1,148,643.85$ & 2.8226 \\
\hline 170 & $320,216.28$ & 0.7869 & 780 & $1,159,369.94$ & 2.8490 \\
\hline 180 & $336,547.67$ & 0.8270 & 790 & $1,170,065.61$ & 2.8753 \\
\hline 190 & $352,634.27$ & 0.8666 & 800 & $1,180,594.14$ & 2.9012 \\
\hline 200 & $368,615.04$ & 0.9058 & 810 & $1,191,187.42$ & 2.9272 \\
\hline 210 & $384,467.00$ & 0.9448 & 820 & $1,201,747.52$ & 2.9531 \\
\hline 220 & $400,586.46$ & 0.9844 & 830 & $1,212,290.10$ & 2.9790 \\
\hline 230 & $416,503.61$ & 1.0235 & 840 & $1,222,814.36$ & 3.0049 \\
\hline 240 & $432,458.07$ & 1.0627 & 850 & $1,233,308.27$ & 3.0307 \\
\hline
\end{tabular}


Table 2 (continued)

\begin{tabular}{llllll}
\hline $\begin{array}{l}\text { Temperature/ } \\
\mathrm{K}\end{array}$ & $\begin{array}{l}{ }^{\mathrm{a}} \text { Molar heat capacity } C_{\mathrm{p}} / \\
\mathrm{J} \mathrm{K}^{-1} \mathrm{~mol}^{-1}\end{array}$ & $\begin{array}{l}\text { Specific heat capacity } C_{\mathrm{p}} / \\
\mathrm{J} \mathrm{K}^{-1} \mathrm{~g}^{-1}\end{array}$ & $\begin{array}{l}\text { Temperature/ } \\
\mathrm{K}\end{array}$ & $\begin{array}{l}{ }^{\mathrm{a}} \mathrm{Molar} \text { heat capacity } \\
\mathrm{J} \mathrm{K}_{\mathrm{p}}^{-1} \mathrm{~mol}^{-1}\end{array}$ & $\begin{array}{l}\text { Specific heat capacity } C_{\mathrm{p}} / \\
\mathrm{J} \mathrm{K}^{-1} \mathrm{~g}^{-1}\end{array}$ \\
\hline 250 & $448,525.24$ & 1.1022 & 860 & $1,243,802.89$ & 3.0565 \\
260 & $464,613.39$ & 1.1417 & 870 & $1,254,247.11$ & 3.0821 \\
270 & $480,482.30$ & 1.1807 & 880 & $1,264,701.32$ & 3.1078 \\
273.15 & $485,536.73$ & 1.1931 & 890 & $1,275,119.16$ & 3.1334 \\
280 & $496,561.52$ & 1.2202 & 900 & $1,285,555.61$ & 3.1591 \\
290 & $512,657.82$ & 1.2598 & 910 & $1,295,968.08$ & 3.1847 \\
298.15 & $525,845.60$ & 1.2922 & 920 & $1,306,412.74$ & 3.2103 \\
300 & $528,603.47$ & 1.2990 & 930 & $1,316,881.33$ & 3.2361 \\
310 & $544,870.45$ & 1.3389 & 940 & $1,327,348.99$ & 3.2618 \\
320 & $560,890.78$ & 1.3783 & 950 & $1,337,847.84$ & 3.2876 \\
330 & $576,798.34$ & 1.4174 & 960 & $1,348,358.98$ & 3.3134 \\
340 & $592,585.99$ & 1.4562 & 970 & $1,358,900.32$ & 3.3393 \\
350 & $608,344.61$ & 1.4949 & 980 & $1,369,496.00$ & 3.3654 \\
360 & $623,974.20$ & 1.5333 & 990 & $1,380,097.42$ & 3.3914 \\
370 & $640,158.71$ & 1.5731 & 1000 & $1,390,725.78$ & 3.4175 \\
\hline
\end{tabular}

${ }^{\mathrm{a}}$ Molar heat capacity was obtained by multiplication of specific heat capacity by the value of the molar mass $\left(M_{\mathrm{w}}\right)$ where the molar mass of collagen is $M_{\mathrm{w}}=406,940.3 \mathrm{~g} \mathrm{~mol}^{-1}$

temperature data, between 5 and $300 \mathrm{~K}$, with an error of $\pm 3 \%$. This agreement supports the conclusion that the only contribution to the low-temperature temperature heat capacity below any phase transition (helix-coil, glass transition) temperature for dry collagen comes from the vibrational motion of the amino acid components.

The total calculated vibrational heat capacity of dry collagen extended to high temperature can be used as the reference line (baseline) in the transition regions for quantitative thermal analysis. The experimental heat capacity of the non-crystalline solid such as dry collagen when approaching the transition regions increases beyond the vibrational limit due to the large-amplitude motion from conformational, and external (anharmonic) contributions [51-54], and can be estimated in the coming study.

For biomacromolecules such as collagen and the collagen-water system, the extrapolated vibrational heat capacity can serve as the baseline also in the high-temperature range beyond the degradation (decomposing) temperature (at about $530 \mathrm{~K}$ ) (Ref. [47]) and is still useful for discussions of thermal stability. It should be noted that collagen shows such degradation above $530 \mathrm{~K}$ during heating at rates up to about $20-30{ }^{\circ} \mathrm{C} \mathrm{min}^{-1}$ for conventional calorimetry (DSC). Today using fast scanning calorimetry (FSC) $[55,56]$ with scanning rates up to $10^{6} \mathrm{~K} \mathrm{~s}^{-1}$, the degradation of collagen might be avoided and any thermal processes examined. The process might be also needed for the analysis of deviation from the baseline $C_{\mathrm{p}}$ line at high temperature caused by laser damage or

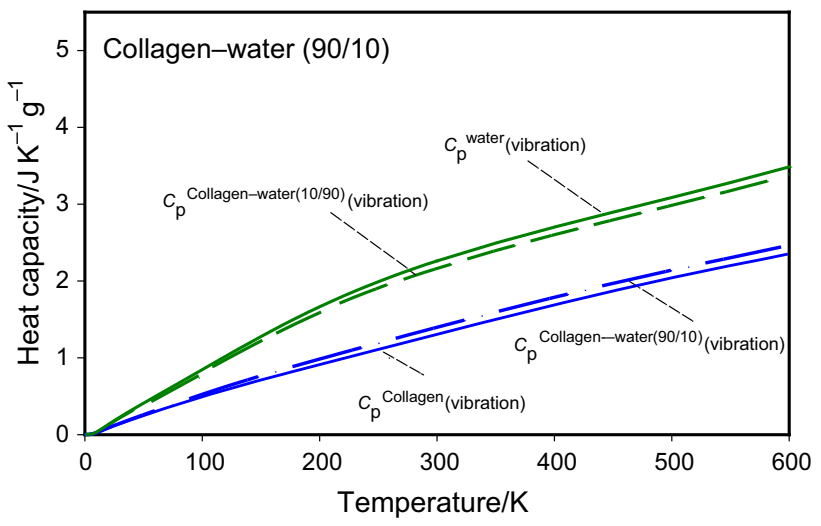

Fig. 5 Calculated vibrational heat capacity of the collagen-water system as a function of temperature for different contents of water, $90 \%$ (green) and 10\% (blue) by mass. (Color figure online)

ablation reaction effects. Thus, the extension of the vibrational $C_{\mathrm{p}}$ can be useful.

\section{Heat capacity of collagen-water system}

Figure 5 presents examples of the vibrational calculated heat capacity of the solid collagen-water system estimated on the basis of the linear combination of fractions of the vibrational heat capacities of both dry collagen and water according to Eq. (10). Results of $C_{\mathrm{p}}^{\text {Collagen-water(10/90) }}$ (vibration) and $C_{\mathrm{p}}^{\text {Collagen-water(90/10) (vibration) are presented }}$ versus temperature for collagen with 10 (blue) and 90 (green) mass\% water, and these are additionally compared 


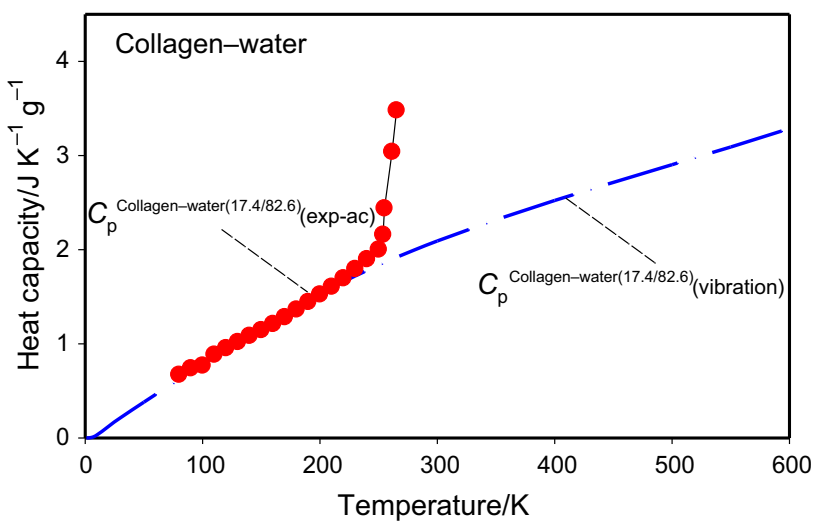

Fig. 6 Comparison of the experimental heat capacity of collagenwater system (17.4/82.6 in mass\%) obtained from adiabatic calorimetry to the calculated vibrational heat capacity as functions of temperature. The experimental data for bovine collagen with completely crystalline excess water were taken from Refs. $[18,24]$

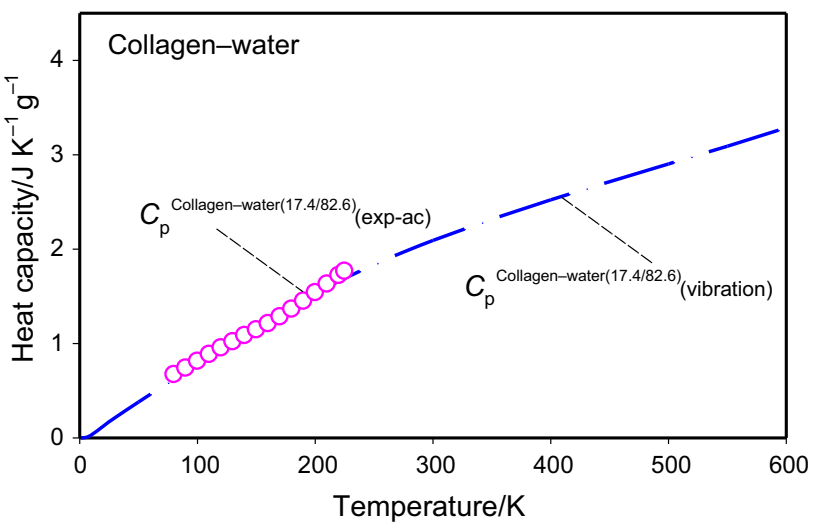

Fig. 7 Comparison of the experimental heat capacity of collagenwater $(17.4 / 82.6$ in mass \%) from adiabatic calorimetry $[18,24]$ to the calculated vibrational heat capacity as functions of temperature for bovine collagen with partially crystalline and vitreous excess of water

with the vibrational calculated heat capacity of dry collagen, $C_{\mathrm{p}}^{\text {Collagen }}$ (vibration), and water, $C_{\mathrm{p}}^{\text {Water }}$ (vibration).

For both cases, the vibrational heat capacity of collagen-water was estimated according to Eq. (10) with the same contribution of $C_{\mathrm{p}}^{\text {Collagen }}$ (vibration) and water, $C_{\mathrm{p}}^{\text {Water }}$ (vibration), for each case and different values of the mass fraction, $f_{\mathrm{S}}$, for collagen equal to $0.90,0.10$ and different values of the mass fraction, $f_{\mathrm{W}}$, for water equal to $0.10,0.90$, respectively.

In Fig. 5, the heat capacity of water is observed to be greater than for collagen at each investigated temperature, and thus, the amount of water in the system of collagenwater increases its ability to increase the heat capacity.

The vibrational heat capacity of the collagen-water system, $C_{\mathrm{p}}^{\text {Collagen-water (vibration), can be used as a reference }}$ baseline for quantitative thermal analysis of the experimental heat capacity of collagen with water.
Figures 6 and 7 show examples of the comparison of the calculated vibrational heat capacity, $C_{\mathrm{p}}^{\text {Collagen-water(17.4/ }}$ ${ }^{82.6)}$ (vibration), with the experimental heat capacity of the bovine collagen with 82.6 mass $\%$ water, $C_{\mathrm{p}}^{\text {Collagen-water(17.4/ }}$ ${ }^{82.6)}$ (exp-ac), measured by adiabatic calorimetry according to Refs. [18, 24]. The calculation of the vibrational heat capacity of collagen-water was conducted according to Eq. (10) for both cases, with the same mass fractions of collagen, $f_{\mathrm{S}}(=0.174)$, and water, $f_{\mathrm{W}}(=0.826)$, respectively. The small difference in experimental heat capacity below melting of fully crystalline water was observed by the authors in Refs. $[18,24]$ in comparison with $C_{\mathrm{p}}$ of collagen with partially crystalline and vitreous water.

Figure 6 illustrates an example for bovine collagen with 82.6 mass \% completely crystalline excess of water in the range of temperature between 80 and $300 \mathrm{~K}$. Figure 7 presents data for bovine collagen with the same amount 82.6 mass $\%$, but partially crystalline and vitreous excess of water between 80 and $225 \mathrm{~K}$. Both experimental data in Figs. 6 and 7 were taken from Refs. [18, 24]. The experimental heat capacity $C_{\mathrm{p}}^{\text {Collagen-water(17.4/82.6) }}$ (exp-ac) below any transition temperature until $220 \mathrm{~K}$ for both examples shows good agreement with calculated vibrational $C_{\mathrm{p}}^{\text {Collagen-water(17.4/82.6) }}$ (vibration).

The agreement between the experimental data and the calculated vibrational heat capacity of bovine collagen with a completely crystalline excess of water was found between 100 and $220 \mathrm{~K}$, with an average relative error of $\pm 1.8 \%$. These findings confirm that the contribution to the heat capacity of collagen-water (17.4/82.6\% mass) comes from vibrational motion of the collagen and water molecules.

In Fig. 6, the small deviation of the experimental heat capacity of collagen-water (17.4/82.6 in mass\%), $C_{\mathrm{p}}^{\text {Collagen-water(17.4/82.6) }}$ (exp-ac), from the vibrational heat capacity, $C_{\mathrm{p}}^{\text {Collagen-water(17.4/82.6) (vibration), is found to start }}$ around $210 \mathrm{~K}$ and increases until $275 \mathrm{~K}$ due to an endothermic transition process, melting of completely crystalline excess of water. More details regarding phase transitions occurring in collagen-water (17.4/82.6 in mass\%) system can be find in Refs. [18, 24]. Knowing the

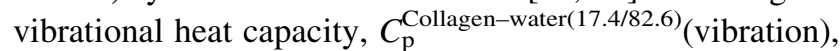
it is possible to analyze qualitatively thermal properties of bovine collagen with completely crystalline excess of water.

Also, the vibrational heat capacity, $C_{\mathrm{p}}^{\text {Collagen-water(17.4/ }}$ ${ }^{82.6)}$ (vibration), for bovine collagen with partially crystalline and vitreous excess of water can be used as reference baseline, for collagen with the presence of 82.6 mass \% of water, and enables qualitative thermal analysis of the experimental data. As it can be observed in Fig. 7, non-phase transitions occur for presented experimental data. Good agreement between the experimental 
data of heat capacity of collagen-water (17.4/82.6 in mass $\%) C_{\mathrm{p}}^{\text {Collagen-water(17.4/82.6) }}(\mathrm{exp}-\mathrm{ac})$ and the calculated vibrational heat capacity $C_{\mathrm{p}}^{\text {Collagen-water(17.4/82.6) (vibration) }}$ of bovine collagen partially crystalline and vitreous excess of water was observed for temperature between 100 and $220 \mathrm{~K}$ with an average relative error of $\pm 2.1 \%$.

\section{Conclusions}

Heat capacity is an important quantity for the characterization of thermal properties of large biomacromolecules such as collagens. Quantitative thermal analysis of all nonequilibrium processes and states needs reference baselines of solid, vibrational heat capacity and the liquid heat capacity.

The heat capacities in the solid state of bovine collagen with and without water were determined based on the contribution of vibrational motions of the components: poly(amino acid)s and water, as presented in Figs. 2-7. The heat capacities of dry collagen and collagen-water were linked to their vibrational spectra. The heat capacities, of dry collagen and collagen-water, were linked to their vibrational spectra. The heat capacity of the solid collagenwater system, below any phase transitions (helix-coil, melting, glass transition), was estimated from a sum of linear combinations of the mass fractions of the vibrational heat capacity of dry collagen and glassy water. Good agreement between the experimental data and the calculated vibrational heat capacity of bovine collagen was observed below any transitions. This agreement supports the conclusion that the only contributions into the experimental heat capacity of solid collagen and the collagenwater system, below any phase transitions, come from the vibrational motions of the amino acid components and water. For example, the heat capacity of bovine collagen with 82.6 mass\% completely crystalline excess of water increases beyond the vibrational limit when approaching the endothermic transition due to the heat of fusion and the large-amplitude motion and can be estimated from conformational, and external (anharmonic) contributions in the crystalline phase. The differences between experimental and vibrational heat capacities above the transition temperature can provide quantitative information about those conformational and anharmonic heat capacities and their motions coming from collagen and water for the processes occurring in the dry bovine collagen and collagen-water system and can be the subject of the future study.

The approach presented here can be applied for the determination of the vibrational heat capacities' reference baselines for quantitative thermal analysis of other biomaterials. The solid-state heat capacity is a fundamental thermal parameter which can be predicted from theories of the vibrational states of matter. Many processes in biology require knowledge of changes in heat capacity, such as protein-protein interactions, glass-to-rubbery transition, protein folding and denaturation, crystallization, and helixcoil transitions, to name a few. Heat capacity measurements are especially important in systems where water is present, owing to the very large heat capacity of the water component. The current work therefore provides the procedure for determining the underlying baseline heat capacity for subsequent calculation of heat capacity changes in systems that can absorb water, as demonstrated for the specific case of collagen type I.

\section{Supplementary data}

- The experimental heat capacities, $C_{\mathrm{p}}^{\text {Collagen }}$ (exp-ac) data, of dry bovine collagen as a function of temperature measured by adiabatic calorimetry;

- The experimental heat capacities, $C_{\mathrm{p}}^{\text {Collagen }}(\exp -\mathrm{ac})$ data, of dry bovine collagen-water (mass\% 17.4/82.6) as a function of temperature measured by adiabatic calorimetry.

Acknowledgements PC thanks the National Science Foundation, Polymers Program, under Grant DMR 1608125, for support. The authors thank Prof. V. Uryash, for providing full experimental data from DSC measurements published in Refs. [18, 24].

Open Access This article is distributed under the terms of the Creative Commons Attribution 4.0 International License (http://creative commons.org/licenses/by/4.0/), which permits unrestricted use, distribution, and reproduction in any medium, provided you give appropriate credit to the original author(s) and the source, provide a link to the Creative Commons license, and indicate if changes were made.

\section{References}

1. Blum RS. The collagen family. Cold Spring Harb Perspect Biol. 2011;3:1-19.

2. Prockop DJ, Wiliiams CJ. Structure of the organic matrix: collagen structure (Chemical). In: Nancollas G, editor. Biological mineralization and demineralization. Berlin: Springer; 1982. p. 161-4.

3. Fratzl P. Collagen: structure and mechanics, an introduction. Collagen: Springer; 2008. p. 10-2.

4. Bella J, Eaton M, Brodsky B, Berman HM. Crystal and molecular structure of a collagen-like peptide at 1.9 A resolution. Science. 1994;266(5182):75-81.

5. Goodsell DS, RCSB Protein Data Bank April 2000. http:// pdb101.rcsb.org/motm/4. Accessed 24 Oct 2018.

6. ProtParam tool, (2018). http://www.expasy.ch/cgi-bin/protpar am1?P02465@noft@. Accessed 24 Oct 2018.

7. Kramer RZ, Bella J, Mayville P, Brodsky B, Berman HM. Sequence dependent conformational variations of collagen triplehelical structure. Nat Struct Mol Biol. 1999;6(5):454. 
8. Ramachandran G. Molecular structure of collagen. Int Rev Connect Tissue Res. 1963;1:127-82.

9. Pyda M, Hu X, Cebe P. Heat capacity of silk fibroin based on the vibrational motion of poly (amino acid) $\mathrm{s}$ in the presence and absence of water. Macromolecules. 2008;41(13):4786-93.

10. Pyda M. Conformational contribution to the heat capacity of the starch and water system. J Polym Sci Part B Polym Phys. 2001;39(23):3038-54.

11. Pyda M. Quantitative thermal analysis of carbohydrate-water systems. In: Lorinczy D, editor. The nature of biological systems as revealed by thermal methods. Berlin: Springer; 2004. p. $307-32$.

12. Sugisaki M, Suga H, Seki S. Calorimetric study of the glassy state. IV. Heat capacities of glassy water and cubic ice. Bull Chem Soc Jpn. 1968;41(11):2591-9.

13. Kanagy JR. Specific heats of collagen and leather. J Res Natl Bur Stand. 1955;55(4):191-195.

14. Del Campo F, Paneque A, Ramirez J, Losada M. Thermal transitions in collagen. Biochem Biophys Acta. 1963;66:448-52.

15. Andronikashvili E, Mrevlishvili G, Japaridze GSh, Sokhadze V, Kvavadze K. Thermal properties of collagen in helical and random coiled states in the temperature range from 4 to $300^{\circ} \mathrm{K}$. Biopolym Orig Res Biomol. 1976;15(10):1991-2004.

16. Horgan DJ, King NL, Kurth LB, Kuypers R. Collagen crosslinks and their relationship to the thermal properties of calf tendons. Arch Biochem Biophys. 1990;281(1):21-6.

17. Tsereteli G, Belopolskaya T, Grunina N, Vaveliouk O. Calorimetric study of the glass transition process in humid proteins and DNA. J Therm Anal Calorim. 2000;62(1):89-99.

18. Uryash V, Sevast'yanov VI, Kokurina NY, Porunova YV, Perova NV, Faminskaya LA. Heat capacity and physical transitions in collagen and solubility of water in it. Russ J Gen Chem. 2006;76(9):1363-7.

19. Samouillan V, Delaunay F, Dandurand J, Merbahi N, Gardou J-P, Yousfi M, Gandaglia A, Spina M, Lacabanne C. The use of thermal techniques for the characterization and selection of natural biomaterials. J Funct Biomater. 2011;2(3):230-48.

20. Hu X, Raja WK, Tokareva B, An O, Cebe P, Kaplan DL. Stability of silk and collagen protein materials in space. Sci Rep. 2013;3:3428.

21. Badea E, Usacheva T, DellaGatta G. The use of differential scanning calorimetry to characterise collagen deterioration in parchment. Rossiiskii Khimicheskii Zhurnal-Zhurnal Rossiiskogo Khimicheskogo Obshchestva im. DI Mendeleeva (Russ Chem J). 2015;59(1):28-41.

22. Gauza-Włodarczyk M, Kubisz L, Mielcarek S, Włodarczyk D. Comparison of thermal properties of fish collagen and bovine collagen in the temperature range 298-670 K. Mater Sci Eng C. 2017;80:468-71.

23. Schroepfer M, Meyer M. DSC investigation of bovine hide collagen at varying degrees of crosslinking and humidities. Int J Biol Macromol. 2017;103:120-8.

24. Uryash V, Gruzdeva A. Thermodynamics of biologically active substances (in russian). Saarbrücken: LAP Lambert Academic Publ.; 2017.

25. Roles K, Wunderlich B. Heat capacities of solid poly (amino acids). I. Polyglycine, poly (l-alanine), and poly (l-valine). Biopolym Orig Res Biomol. 1991;31(5):477-87.

26. Roles K, Xenopoulos A, Wunderlich B. Heat capacities of solid poly (amino acid) s. II. The remaining polymers. Biopolym Orig Res Biomol. 1993;33(5):753-68.

27. Di Lorenzo M, Zhang G, Pyda M, Lebedev B, Wunderlich B. Heat capacity of solid-state biopolymers by thermal analysis. J Polym Sci Part B Polym Phys. 1999;37(16):2093-102.

28. Wunderlich B. Thermal analysis of polymeric materials. New York: Springer; 2005.
29. Wunderlich B. Quasi-isothermal temperature-modulated differential scanning calorimetry (TMDSC) for the separation of reversible and irreversible thermodynamic changes in glass transition and melting ranges of flexible macromolecules. Pure Appl Chem. 2009;81(10):1931-52.

30. Wunderlich B. Thermal analysis. New York: Academic Press; 1990.

31. Wunderlich B. The ATHAS database on heat capacities of polymers. Pure Appl Chem. 1995;67(6):1019-26.

32. Pyda M. Temperature-modulated differential scanning calorimetry. In: Encyclopedia of polymer science and technology, 2014. p 1-30.

33. Cheng SZD, Pan R, Wunderlich B. Thermal analysis of poly(butylene terephthalate) for heat capacity, rigid-amorphous content, and transition behavior. Die Makromolekulare Chemie. 1988;189(10):2443-58.

34. Schick C, Wurm A, Mohamed A. Vitrification and devitrification of the rigid amorphous fraction of semicrystalline polymers revealed from frequency-dependent heat capacity. Colloid Polym Sci. 2001;279(8):800-6.

35. Pyda M, Wunderlich B. Reversing and nonreversing heat capacity of poly (lactic acid) in the glass transition region by TMDSC. Macromolecules. 2005;38(25):10472-9.

36. Pyda M, Czerniecka-Kubicka A. Thermal Properties and Thermodynamics of Poly (L-lactic acid). In: Di Lorenzo M, Androsch $\mathrm{R}$, editors. Synthesis, Structure and properties of poly (lactic acid). New York: Springer; 2017. p. 153-93.

37. Magoń A, Wurm A, Schick C, Pangloli P, Zivanovic S, Skotnicki M, Pyda M. Reprint of "Heat capacity and transition behavior of sucrose by standard, fast scanning and temperature-modulated calorimetry". Thermochim Acta. 2015;603:149-61.

38. Pionteck J, Pyda M. Polymer solids and polymer melts, part 2, thermodynamic properties-pVT-data and thermal propertiesLandolt-Boernstein-Polymer. Heidelberg: Springer; 2014.

39. Pyda M Van, Durme K, Van Wunderlich B, Mele B. Heat capacity of poly (vinyl methyl ether). J Polym Sci Part B Polym Phys. 2005;43(16):2141-53.

40. Magoń A, Pyda M. Study of crystalline and amorphous phases of biodegradable poly (lactic acid) by advanced thermal analysis. Polymer. 2009;50(16):3967-73.

41. Pyda M, Bopp R, Wunderlich B. Heat capacity of poly (lactic acid). J Chem Thermodyn. 2004;36(9):731-42.

42. Czerniecka A, Magoń A, Schliesser J, Woodfield B, Pyda M. Heat capacity of poly (3-hydroxybutyrate). J Chem Thermodyn. 2014;73:76-84.

43. Nernst W, Lindemann F. Specific heat and quantum theory, Z. Electrochem. 1911;17:817-27.

44. Xenopoulos AK, Roles K, Wunderlich B. Polymer a possible glass transition for poly(L-methionine) and poly(L-serine). Polymer. 1993;34(12):2559-63.

45. Tarasov V, Yunitskii GA. Theory of heat capacity of chain and layer structures. Zhurnal Fizicheskoi Khimii (Russ J Phys Chem A). $1950 ; 24: 111$

46. Debye P. Zur theorie der spezifischen wärmen. Ann Phys. 1912;344(14):789-839.

47. Miles CA, Avery NC. Thermal stabilization of collagen in skinand decalcified bone. Phys Biol. 2011;8(2):026002.

48. Pyda M, Zawada P, Cebe P. Vibrational heat capacity of collagen and collagen-water. In: 43th NATAS conference, Montréal, Québec, 2015.

49. Hu X, Kaplan D, Cebe P. Determining beta-sheet crystallinity in fibrous proteins by thermal analysis and infrared spectroscopy. Macromolecules. 2006;39(18):6161-70.

50. Hu X, Kaplan D, Cebe P. Effect of water on the thermal properties of silk fibroin. Thermochim Acta. 2007;461(1-2):137-44. 
51. Pyda M. Conformational heat capacity of interacting systems of polymer and water. Macromolecules. 2002;35(10):4009-16.

52. Pyda M, Wunderlich B. Analysis of the residual entropy of amorphous polyethylene at 0 K. J Polym Sci Part B Polym Phys. 2002;40(12):1245-53.

53. Piorkowska E, Rutledge GC. Melting. In: In: Pyda M, editor. Handbook of polymer crystallization, 2013. p. 265-285.

54. Pyda M, Boller A, Grebowicz J, Chuah H, Lebedev B, Wunderlich B. Heat capacity of poly (trimethylene terephthalate). J Polym Sci Part B Polym Phys. 1998;36(14):2499-511.
55. Minakov, AA, Schick, C. Ultrafast thermal processing and nanocalorimetry at heating and cooling rates up to $1 \mathrm{MK} / \mathrm{s}$. Rev Sci Instrum. 2007;78:073902.

56. Ray VV, Bathia AK, Schick C. Fast isothermal calorimetry of modified polypropylene clay nanocomposites. Polymer. 2007;48:2404-2414.

Publisher's Note Springer Nature remains neutral with regard to jurisdictional claims in published maps and institutional affiliations. 